ISSN 1012-277X S.Afr.j.ind.eng.

$-1-$

S A Journal of Industrial Engineering, vol 8, No 1, June 1994, pp1-16

\title{
TOWARDS A SYSTEMS APPROACH TO OPERATIONS MANAGEMENT
}

\author{
Alp Baysal \\ School of Engineering Management \\ University of Cape Town
}

\begin{abstract}
Since their appearance on earth, humans have always had to deal with different problems. Progress and development have been the results of their success in overcoming these problems. But every problem solved has lead to others, that are usually more complex than the previous ones. Increasing degrees of complexity made it necessary to develop new ways of interpreting our world and tackling our problems.

One of the words that can characterise, the world that we are living in today, the best, is change. Like everything else, the nature of our problems is also changing with an unprecedented speed. We need new and effective approaches and methodologies to deal with them. We cannot use any more the ones that we have inherited from previous generations.
\end{abstract}

\section{OPSOMMING}

Van die verskyning van die mensdom op die wêreld, moes mense verskillende tipes probleme hanteer. Vooruitgang en ontwikkeling het gevolg op die suksesvolle hantering van hierdie probleme. Elke probleem wat opgelos is het egter tot nuwe probleme gelei, gewoonlik meer kompleks as die oorspronklike probleem. Hoër vlakke van kompleksiteit vereis die ontwikkeling van nuwe maniere om die wêreld te interpreteer en probleme aan te pak.

Een van die woorde wat ons huidige wêreld die beste karakteriseer is verandering. Soos byna alles anders, is die aard van ons probleme ook aan die verander, teen ' $n$ versnellende tempo. Daar is ' $n$ behoefte aan nuwe en effektiewe benaderings en metodologië om hierdie probleme te hanteer. Ons kan nie meer benaderings volg wat ge-erf is van vorige geslagte nie. 


\section{Introduction}

This paper is about the general characteristics of todays' business problems, and about a philosophy that can insightfully deal with them. Its objective is to emphasize the need for an approach that can manage complex and dynamic operational issues of a business, and to introduce systems perspective as such an approach. It is structured in the following way.

Part One, The Need For A Systems Approach To Deal With Complexity, is about the nature and characteristics of today's business problems and about a specific environmental factor making these problems different from yesterday's ones, i.e. about change. Ongoing change is considered to be a major factor adding to the complexity of these problems. Different approaches adopted for dealing with them and the strengths of systems perspective as problem identifying and problem solving approaches, are discussed in this part.

After the introduction of general concepts in Part One, in Part Two, The Nature Of Operations Management, the discussion is focused on the context of operations. Here, an overview of Operations Management is given from the perspectives of different authors. Their definitions of the Operations Management, their perceptions of the major problem areas and the mental models that they have developed to structure the operational concepts are explained.

Part Three, A Systemic Approach To Operations Management, deals with the application of systems approach to the operations context. Here, systemic models and operational models that are introduced in Part One and Two are compared. Similarities between them and their complementary nature are emphasized. Also a hybrid model illustrating the systemic interpretation of a specific operational set-up (manufacturing) is presented.

\section{The Need For A Systems Approach To Deal With Complexity}

Continuous and accelerating change in all areas is one of the most important characteristics of today's World. To a large extend, this change is stimulated by the information explosion resulting from inventions and innovations which are increasing in number with a snowball effect. Accumulation of information on its own, would not be translated into the global change that we are experiencing, if it was not possible to communicate the information generated and/or collected, to large masses in an effective and efficient way.

Fortunately, inventions and innovations do not only add to the pool of knowledge of the human race, but they also make information flow much easier and faster than ever before. Global computer networks like INTERNET, global news agencies like CNN and SKY 
NEWS, TELETEXT services offered by different TV channels, international magazines like TIMES, NEWSWEEK, FINANCIAL MAIL, etc... that are printed simultaneously at different centers and distributed all around the world, are some examples of efficacious means which are facilitating the information flow for large masses.

The increasing availability and accessibility of updated information stimulates new inventions and discoveries on one side, and leads to further environmental change on the other side. The spiral of invention/innovation and information acts as a generator supplying the necessary energy and resources for the continuous process of change.

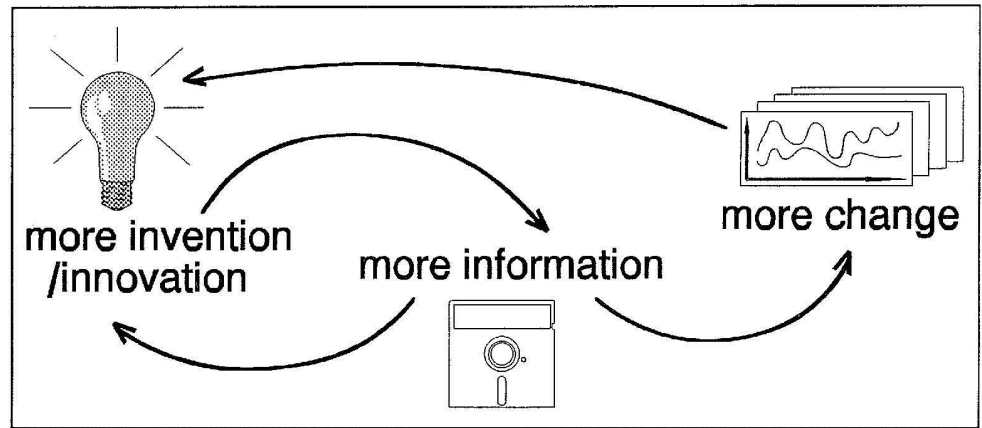

Figure 1

In the reality, the mechanism of change is far more complex than the one presented in FIGURE 1, and several other key elements are involved in it. The following points illustrate the potential level of complexity that the model can reach.

More change create more needs, and to fulfil these needs becomes the target of new research and development projects that will lead to more inventions and innovations. On the other hand, changes in information systems can further facilitate the information flow and thus ensure a more favourable environment for researchers.

Another valid perspective in this context, is the one presented by Kauffman [1] :

Back in prehistoric times, knowledge accumulated very, very slowly. Then the pace began to pick up until... it turned into a knowledge explosion. [...] The more knowledge you have, the better off your society is, and the more people it can support to spend their time looking for more knowledge. One figure that is widely quoted illustrates this very well: $90 \%$ of the scientists who have ever lived are alive and working today! 
Besides its positive effects on the global development, the abundance and the availability of information contributes to the complexity of the world that we are living in. The variety of information brings along the necessity for an information processing and management system. Without such a system, it is very difficult to capture, filter, classify and structure the information and to draw meaningful conclusions from it. It is no good expecting computers to overcome this, because though they can manipulate very large numbers of components, manipulation is not the same as understanding (Carter [2]).

Change will continue to happen and it will make the World a different place than it is today. To keep up with the change, is becoming more and more difficult every day, as its pace goes beyond the individual understanding and adaptation capabilities of individuals. This is true for the business life as well as for our private lives. A typical example from the private life, is the struggle of some parents in understanding different world views and value systems adopted by their kids. However, in the caring family environment, where people believe to higher and uniting values like respect and love for each other, and the joy of being together, it is possible to overcome the consequences of this problem. Whereas in the business life, where the rules of the game are harsher, a deficiency of understanding and interpreting the environment may have very serious results.

In the business environment, the effect of continuous change can be felt in different areas like technology, markets, industrial relations, etc... The impact of the change on the nature of real life problems has a particular importance for managers, who are accepted to be the problem solvers of this environment.

Most of today's business problems are not well defined. They are initially detected as a feeling of discomfort about a situation. It may take a long time until they are clearly defined, or in some cases, this definition can never be made. Because of their multi-facial nature (i.e. the same problem may have different faces, different appearances), to isolate them, is as difficult as trying to solve them.

It is also quite intricate to trace them in time and space as they have a dynamic and metamorphic nature (i.e. they can change their form and structure over time) which is, to a large extent, a consequence of the environmental change. We may be indifferent to the change happening around us, but our problems will not be. In a way, they will use it as a disguise. They will disappear after an intervention, and will reappear at a different time and place in the organisation, with a totally different face, and they will deceive us. We will not be able to detect the reoccurrence of the same chronic problem. We will think that we are now dealing with a new one.

Being multidimensional is another characteristic of today's business problems. They can effect simultaneously different aspects of the same business. Therefore it is almost impossible to crystallise and to analyze them piece by piece, and to experiment the effects of different remedies on them. Also, the idea of experimenting brings together the concept of trial and error, and not many businesses can afford to learn about their problems by running real life experiments on their organisations. 
In practice, problem situations are usually observed in an environment which cannot be controlled directly by the observer. The typical outcome of such observations is a set of data about the variations of parameters which are considered to be critical for a given problem context. Critical parameter consideration may vary from business to business. Also the focus of the observation can effect the selection of these parameters.

The success of the manager lies in his/her ability to interpret this data set in an insightful way. This requires some level of experience, availability of data processing tools and decision making aids, updated background knowledge about the situation and, the most important of all, a relevant approach for a given context. These prerequisites are necessary to identify the problem as well as to implement the corrective action.

The depth of understanding that one can reach while studying a complex issue, depends to a large extent on the approach used. On this topic, Senge [3] states :

There are multiple levels of explanation in any complex situation. In some sense all are equally true. But their usefulness is quite different.

The concept of multiple levels of explanation is illustrated graphically in FIGURE 2. Each approach in this figure can be evaluated according to two criteria :

its scope, which is the indication of the elemental variety considered by the approach,

- $\quad$ its penetration, which is the indication of the depth that the approach can reach while explaining a situation.

If the approach of the manager trying to interpret a problematic situation, is purely symptomatic, i.e. if his/her focus is mainly on events, then this approach is described as a reactive one. A reactive approach uses simplistic causality relations to explain the reasons (causes) of problematic outcomes (symptoms). Both causes and symptoms are defined at the event level, and usually in a narrow time frame. Symptomatic approaches tend to oversimplify problem contexts and they neglect their structural complexity. Their scope is quite limited and their penetration stays at a superficial level.

Interpretations based on behavioural patterns can identify longer term trends. At the global level, they can give some guidelines about the response of a system to a change in its environment, but they do not explain the response mechanism. They begin to break the grip of short term reactiveness (Senge [3]). Although they cannot bring a specific explanation to a problematic situation (shallow penetration), they can give a better insight about the variety involved (wider scope) than event explanations. In fact interpretations based on behavioural patterns are quite cautious about running into conclusions. They report the pattern of behaviour of a variable observed over a period of time. But they do 
not relate this behaviour directly to a cause. In other words, they do not give an explicit answer about the causes of a problematic outcome, but they do not misguide the decision maker by suggesting simplistic assumptions either.

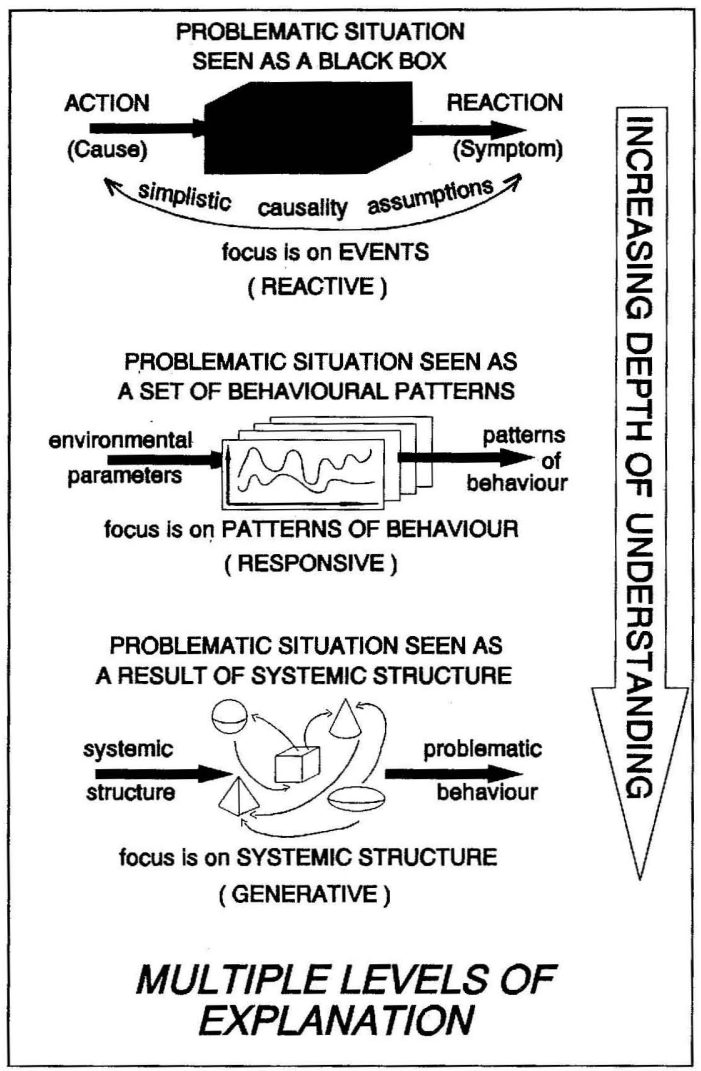

Figure 2

About the third level of explanation which focuses on the structure itself, Senge [3] makes the following comment :

The structural explanation, is the least common and the most powerful one. It focuses on answering the question, "What causes the patterns of behaviour?" [...] Though rare, structural explanations, when they are clear and widely understood, have considerable impact. 
Structural explanations go beyond the cautious interpretation of patterns of behaviour explanations. They argue that the systemic structure is the underlying cause of the problematic outcome. They also appreciate the complexity of this structure and allocate considerable time and energy to understand the key structural elements and the relationships between them. They study a situation both horizontally (wide scope) and vertically (deep penetration).

The level of explanation used by managers while interpreting a real life problem situation is crucial for the long-term success of any corrective action. For example event explanations tend to establish a fairly direct and obvious causality relationships between the events and their assumed causes. Because of the simplistic image that they create, they give the impression that they can bring the fastest and the most effective relief. Therefore, they are a very attractive alternative for managers who are under the pressure of doing something quickly about a problem situation. Unfortunately, most of the times, they only bring a short-term symptomatic relief. The problem that disappears after the intervention reappears sometime in the future at the same place or at some different place in the organisation.

In complex systems, cause and effect are generally not closely related in time and space. As managers, we typically assume they are (Senge [3]). This misconception about causality can be very deceptive. Approaches neglecting the complexity of the causal relations in organisations condemn their followers to waste their time and energy with low-leverage intervention points.

In an organisation which is experiencing a problematic situation, usually there is a small number of intervention points that can bring dramatic and enduring improvements. But unfortunately the complex causality structure hides these points from the eye of managers using traditional reductionist approaches. Therefore these points are called non-obvious high-leverage points.

On the other hand, a reactive approach that interprets the causality structure in a simplistic way, can highlight quickly a few obvious low-leverage points. An intervention directed to one of these points, which is normally easy to locate, will make the symptom disappear but it will not cure the problem. When the long term success of an intervention is considered, to focus on low-leverage points is a waste of time, energy and resources. It may also lead to an intervention addiction.

Intervention addiction is the chronic pattern of using short term symptomatic reliefs to bring temporary improvements to a problematic situation. As these interventions deal only with the symptoms and leave the essence of the problem intact, the improvement that they bring lasts only for a limited time. After a while the problem shows its presence again, by surfacing similar or different symptoms. 
Traditional approaches tend to identify the causes of problematic behaviours in the external environment. Consequently, they encourage the attitude of blaming the uncontrollable external factors as the causes of the organisational problems. In other words, they put the organisation in the position of a helpless victim of its environment.

On the other hand, the systemic approach focuses on the organisation as a whole. Its essence is the notion that, problems arise from the interactions of different parts of a system. The system itself causes its behaviour. This perception liberates the system of being the victim of its environment. It highlights the possibility of improving the systemic behaviour, even under very unfavourable environmental conditions. Systems perspective does this by focusing on the underlying structure of interconnected relations among different processes and elements, that gives each system its unique character.

The following list summarises the basic contrasts between two approaches :

\author{
Traditional Approach \\ * Reductionist \\ * Focus on problematic \\ behaviours (symptomatic) \\ * Focus on obvious low-leverage \\ points \\ * Non-controllable external \\ environment as the cause of the \\ problematic behaviour \\ * Intervention addiction \\ * Narrow scope \\ * Shallow penetration
}

\section{Systemic Approach}

* Holistic

* Focus on systemic structure (structural)

* Focus on non-obvious high-leverage points

* The system itself as the cause of its problematic behaviour

* Improvement sustainable in the long term

* Wide scope

* Deep penetration

\section{The Nature of Operations Management}

Today's concept of Operations Management (OM) has evolved from Industrial Management and Manufacturing Management concepts that were first used some fifty years ago. The reason for the change in terms was that, concepts and techniques for managing production in factories have been found to be useful in government and services as well. 
When we look at different modern textbooks in operations management (also known as Production and Operations Management - POM) we observe that more or less the same topics are covered in all of them. The differences are in the frameworks used to cover these topics.

The first approach to operations management, that will be considered here, is the one of Shonberger [4]. He defines operations management as the management of ends and means. According to Shonberger [4], productive operations resulting in goods and services, are the ends, and operating resources are the means. He uses his Functional Model of Operations and Operating Resources Management to cover and to group different areas of operations management.

His functional model divides OM initially into two major areas :

OM functions that are concerned with managing the operations (producing the outputs),

OM functions that are concerned with managing the resources used in operations (the inputs).

Each of these two major functional areas are further subdivided into three zones :

Advance planning,

Action planning,

- Control.

Shonberger [4] describes these zones in the following way :

Advance planning is longer range and strategic. Action planning is shorter range and tactical. Control involves keeping track of how well the operations are conforming to the plans.

According to Shonberger [4], operations functions of an organisation can be represented by a matrix structure (functional grid) consisting of six subdivisions (advanced planning for outputs, action planning for outputs, control for outputs, advanced planning for inputs, action planning for inputs and control for inputs). Different OM concepts are in fact different elements of this matrix structure, that are connected to each other by some information links.

On the other hand Chase and Aquilano [5]have a different approach to production and operations management. They call it a life cycle approach and they define it in the following way (Chase and Aquilano [5]) : 
The structure, which we have termed the life cycle approach, follows the progress of the productive system from its inception to its termination.

In this approach the life cycle of a productive system is divided into the following five stages :

\author{
- $\quad$ Birth of the system \\ Product design and process selection \\ - Design of the system \\ - $\quad$ Startup of the system \\ The system in steady state
}

Different operations management topics are then allocated to the stages of the life cycle. Precedence relations between these stages are used to connect various operations concepts, and thus to form a framework .

Chase and Aquilano [5], put a special emphasis on direct resources. They define operations management as the management of direct resources required to produce the goods and services provided by an organization (Chase and Aquilano [5]). These resources may be thought of as the five P's of operations management : people, plants, parts, process, planning and control.

A third approach to operations management that will be reviewed here is the one of Ray Wild [6]. This one differs from the others by the special emphasis that it puts on the structure of an operating system. In his book Production and Operations Management Ray Wild [6] states :

Given the influence of the basic operating system structure, one principal aim of operations management will be to select the system structure to be employed or, failing that, to influence its selection.

There are important similarities between Senge's [3] and Wild's [6] perspectives of structure. For Senge [3], the systemic structure is primarily concerned with interrelationships of key variables that influence the systemic behaviour over time. Whereas Wild [6] argues that there is a direct relationship between the structure of the operating system, principal problem areas and problem characteristics. According to Wild [6] :

If a system is designed to have, or if it must normally have a certain structure, the strategies adopted by the management should reflect the needs and constraints of that system structure. 
Wild [6] classifies principal problem areas of operations management under three main headings :

\author{
- Inventory Management \\ Scheduling \\ - Capacity Management
}

He relates the complexity in principal problem areas to the close interdependence among them.

One factor adding considerably to the complexity of inventory, capacity and scheduling problems is their close interdependence. Decisions taken in one will have a direct impact on performance in the others (Wild [6]).

All three approaches to operations management cover more or less same operational concepts. The difference between them stems from the structure that they use to organise these concepts, and to define the operations environment. Among all, Wild's [6] interpretation of operations management, is the one with the highest systemic content. Concepts like the structure causing its own behaviour and the complexity being the result of interactions between structural elements, are largely used in this approach. Therefore his perspective and his conceptual model are the most suitable ones to be a common ground to amalgamate operations management and systems concepts.

\title{
3. A Systemic Approach to Operations Management
}

If the objective is to improve the problematic behaviour of an operating system, to study its structure is a good starting point. As the structure effects the behaviour, to understand it, will give some insight about the general characteristics and possible patterns of behaviours that can be expected from a specific operating system. But on its own, this global understanding, will not help much to go to the roots of the problem situation, to determine high-leverage intervention points, and to develop alternative ways of bringing sustainable improvements. In order to reach these objectives, operations management methods have to be used together with systems methodologies within a systemic framework. Different perspectives adopted by these two approaches and their complementary nature is illustrated in FIGURE 3. Once the generic structure has been defined from operations management perspective, one can use systemic approach to develop an understanding of the parts and to integrate this understanding back into a larger whole.

In this discussion, Wild's [6] definition of structure (i.e. the way physical storage, input/output flows and customers are organised around the transformation process) is 
referred to, as operational structure, and Senge's [3] definition of structure (i.e. key variables and interrelations between them that influence the systemic behaviour over time) as systemic structure. It is argued that a holistic understanding of an operating system is possible by discovering its operational structure and its systemic structure together. Alternative ways of improving an actual problematic situation will emerge from this understanding.

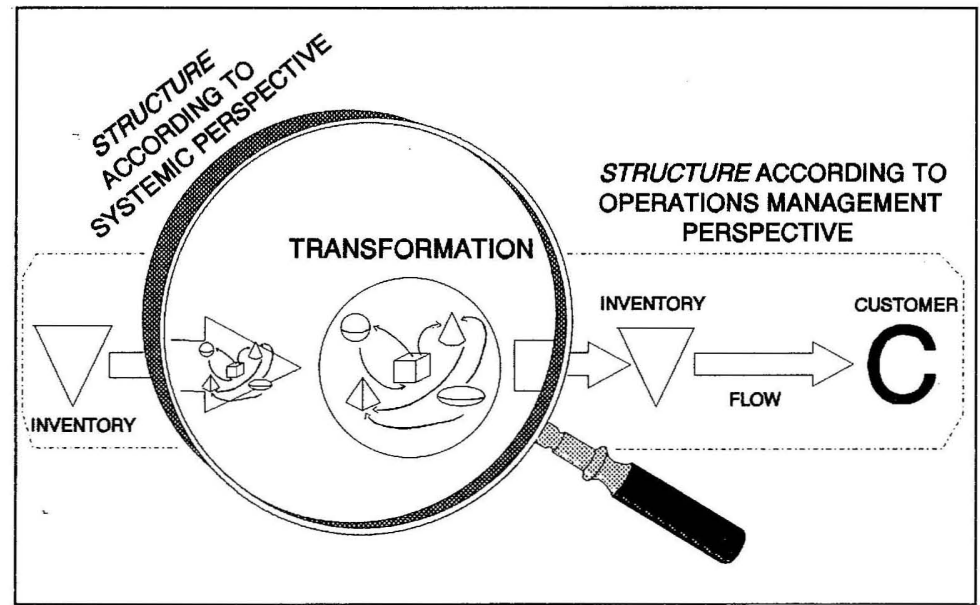

Figure 3

Systems perspective can be used in operations management context to :

- identify the underlying causes of problematic behaviours in today's manufacturing environment by ensuring a holistic understanding of relevant operating systems,

- develop and evaluate alternative ways of bringing sustainable improvements to actual problematic situations.

A holistic unders ${ }^{+}$nding of an operating system enables the problem solver to identify the underlying causes of symptoms, and to distinguish high- from low-leverage intervention points in the system. As it is mentioned earlier, interventions at high-leverage points have a dramatic and enduring impact whereas interventions at low-leverage points have only an ephemeral effect on the system.

However, it is not easy to identify high-leverage points, especially if the approach used is non-systemic. The high-leverage points are not closely related in time and space to the obvious symptoms of the problem. Because the connection between short and long term 
response is often unrecognized, intervenors can get drawn into a reinforcing spiral of intervention (intervention addiction). The longer the delay between short and long term response, the more likely is the repeated use of an ineffective intervention (Senge [3]).

A person who is adopting a systemic approach to deal with a problematic situation, will have to choose a specific method(s), at some stage of the study, from the several ones available in systems literature. But this choice is not straightforward. On this issue Flood and Jackson [7] make the following comments :

A major difficulty for managers and management scientists seeking to use systems thinking is knowing how to employ the range of different systems approaches available. [...] Each approach has been tried and tested and works well in some circumstances. [...] Fortunately, it is possible to provide guidelines that point to the respective strengths of different systems approaches and suggest when a situation favours the use of one rather than the other.

There are important similarities between the elements of Wild's [6] operational structure and Senge's [3] systemic structure as shown in FIGURE 4. Senge's [3] perspective is based on a systemic approach called System Dynamics (SD). In this approach, a level represents a quantity that accumulates over time, and a rate represents an activity, or movement, or flow that contributes to the change per unit of time in a level. These structural similarities naturally make system dynamics a suitable systemic approach to be used in a manufacturing context where Wild's [6] principles of operations management are adopted.

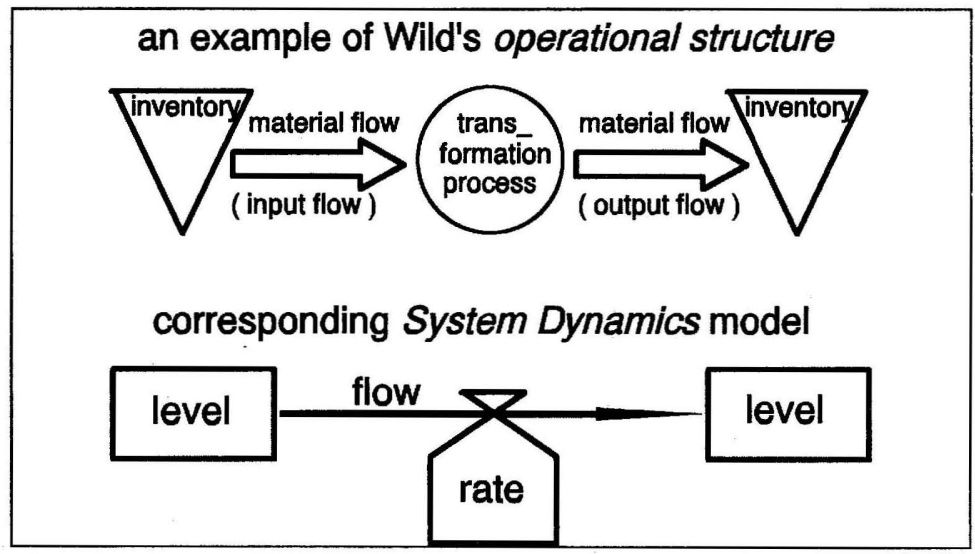

Figure 4 
In addition to material flows shown in FIGURE 4, SD can also represent information flows between different elements of the operating system. Information flows generally influence rates and they add important behavioural characteristics to the model.

SD is a methodology for understanding certain kinds of complex problems. It began some thirty years ago as industrial dynamics, focusing on problems arising in the corporate setting. The initial ideas of SD can be attributed to Jay Forrester and his work at MIT.

Flood and Jackson [7] define the philosophy of SD in the following way :

A system dynamics view is one that places emphasis on structure, and the process within that structure, assuming that this is how dynamic behaviour in the real world can best be characterised. SD, then, considers behaviour as being principally caused by structure, it is a theory of the structure of systems and dynamic behaviour. [...] SD assumes that analysis of a situation can be undertaken from an external objective viewpoint and that the structure and dynamic process of the real world can be re-created in both systems diagrams and mathematical models.

However, it is accepted that, the real world is too complex to be re-created in any kind of model. Therefore SD models should not be seen as the exact representation of the real world. They should rather be taken as the ways of organising our thinking about realities.

In fact to obtain the final model is only a part of the objective. The understanding that the modeller develops while building the model and the resulting shift of thinking in his/her mind are more important than the final model itself. The final model is only a tool that can approximate the behavioural patterns of key system variables, and thus, that can contribute to the decision making process.

\section{Conclusion}

Our World is changing wi+.i. a speed that has never been experienced before in the human history, and so are our problems. We cannot expect to solve them by using the conventional management methods which are assuming a fairly straight forward link between the causes and symptoms.

The simplistic idea behind this causality perspective is that cause and effect are closely related in time and space. When problem arises, it is assumed that the causes lie in the same part of the system as the problem itself. It is also assumed that, once the appropriate local remedy is applied, the problem will be solved relatively quickly.

From a systemic perspective, cause and effect generally are not closely related in time and 
space. Causes of a problem may lie in a completely different part of a system from the problem symptoms. Therefore we must look beyond the apparent causal relations.

Most of the times, the system structure itself is responsible for the systemic behaviour. Therefore it is necessary to understand the underlying structure in order to locate the real causes of problem behaviours and to be able to do relevant structural changes that will bring sustainable improvements. System structure is concerned with the interrelationships among key variables that influence the behaviour over time. Once the structural explanation of the undesired systemic behaviour is found, then it is necessary to correct this structural deficiency to improve the behaviour. Symptomatic interventions based on simplistic causal explanations will not have the desired effect unless the systemic structure is right.

Continuous and accelerating change and its impact on the nature of today's business problems will make the traditional management approach to problem solving, less and less effective. This symptomatic approach which is stuck in event explanations will only see a chaos in the multi-facial, and multi-dimensional complex problems of today's world. In this world of complex systems, systemic approaches that can see an order in today's chaotic problems, through their structural explanations, will generate solutions that can bring improvements sustainable in the long term. 


\section{REFERENCES}

[1] Kauffman Draper L Jr, 1980, Sytems One: An Introduction To Systems Thinking, Future Sytems.

[2] Carter Ruth; Martin John; Mayblin Bill and Munday Michael, 1984, Systems, Management And Change, Harper \& Row.

[3] Senge Peter M, 1990, The Fifth Discipline, Doubleday Currency.

[4] Schonberger Richard J, 1985, Operations Management, Productivity and Quality, Business Publications Inc.

[5] Chase Richard B.; Aquilano Nicholas J, 1989, Production And Operations Management, A Life Cycle Approach, Irwin.

[6] Wild Ray, 1980, Production And Operations Management, Holt Rinehart and Winston.

[7] Flood Robert L; Jackson Michael C, 1991, Creative Problem Solving, John Wiley \& Sons. 